\title{
Regulatory Communication Material
}

National Cancer Institute

\section{Source}

National Cancer Institute. Regulatory Communication Material. NCI Thesaurus. Code

C115611.

A collection of regulatory-related communications, agreements, significant discussions, or relevant information. 